\title{
POST-EMBRIONIC DEVELOPMENT OF THE DIGESTIVE TUBE OF DERMATOBIA HOMINIS (LINNAEUS) (DIPTERA, CUTEREBRIDAE)
}

\author{
Ana Maria Vieira ${ }^{1,2}$ \\ Edy de Lello ${ }^{1}$
}

\begin{abstract}
The digestive tube of $2^{\text {nd }}$ and $3^{\text {rd }}$ instar larvae, pupae and newly emerged adults of Dermatobia hominis (Linnaeus, 1781) was studied anatomically. The specimens were dissected in buffer saline under a stereomicroscope, and the digestive tubes were placed on slides and fixed in $10 \%$ buffered formalin. Each tube was measured using a micrometric eye piece, and drawings were made with camera lucida. The results showed that the midgut, the hindgut and the Malpighian tubules with their ducts grow gradually during the larval development. The oesophagus and the salivary glands with their ducts grow only during the moult from the $2^{\text {nd }}$ to the $3^{\text {rd }}$ instar. In the pupal period, salivary glands grow gradually but disappeared after the $20^{\text {th }}$ day. After metamorphosis the digestive tube regressed. This is expected since adult $D$. hominis lives about nine days without feeding. This fly, similar to other calyptratae muscoid flies shows no vestige of a crop during all post-embrionic development, and the adult has no salivary glands.

KEY WORDS. Dermatobia hominis, digestive tube, anatomy, post-embrionic development.
\end{abstract}

The first references to the anatomy of the digestive tube of Diptera are found in DufFour $(1844,1851)$ apud SINGH \& JUDD (1966) that described the internal anatomy, physiology and life cycle of Diptera in general. Since then many other authors described the anatomy, the physiology and the development of single species LownE $(1893,1895)$, HewitT $(1907,1914)$ apud SiNGH \& JUDD (1966), WEST (1951), BAIRD \& AKRE (1977), DIXON (1952); others described peculiarities of the digestive tube of a given species MINCHIN (1905) apud SINGH \& JUDD (1966), GRAHAM-SMITH (1934), or did comparative descriptions of internal anatomy among different species of a same family (OWSLEY 1946; OKADA 1954a,b; HORI 1960, 1961, 1962a,b; SINGH \& JUDD 1966). Different regions of the digestive tube in Diptera received a number of denominations.

Dermatobia hominis (Linnaeus, 1781) is a calyptratae muscoid, living in the warm regions of the New World, from Mexico to Argentina. The larva is a subcutaneous parasite of several vertebrate hosts, cattle being preferred. It takes about 35 days for the larva to go through three instars (L1, L2 and L3) growing from 1 to $25 \mathrm{~mm}$ of lenght and from 0.3 to $10 \mathrm{~mm}$ of width. Mature larvae drop spontaneously off the host and burrow into soil to pupate. Pupal period takes about 30 days,

1) Departamento de Morfologia, Instituto de Biociências, Universidade Estadual Paulista. 18618-000 Botucatu, São Paulo, Brasil.

2) M.S. Scholarship - CNPq. 
when the imago emerges. The anatomical variation of the digestive tube in $D$. hominis was studied from L2 to newly hatched adult, using the following terminology: foregut (FG) composed of pharynx (ph), oesophagus (oe) and cardia (ca); the midgut (MG); the hindgut (HG), composed of ileum (i), colon (c) and rectum (r). In old pupae and adults, the median region of the rectum is dilated, forming the rectal ampule (a).

\section{MATERIAL AND METHODS}

Digestive tubes of second (L2) and third (L3) instar larvae, pupae and newly hatched adult $D$. hominis were analised. L2 and L3 were obtained by squeezing out of naturally infested bovines. To obtain pupae and adults, heavily infested cattle were kept indoors and mature larvae were collected daily on the ground. The larvae were placed in plastic boxes containing humid soil, and left to pupate. Pupae were maintained at $25^{\circ} \mathrm{C}$ and $70-80 \%$ relative humidity in a BOD incubator. Adults emerged 30-35 days later.

Second instar larvae weighed from 35 to $50 \mathrm{mg}$ and third instar larvae weighed from 78 to over $600 \mathrm{mg}$. Pupae were dissected from the first to the $33^{\text {th }}$ day.

The specimens were dissected under stereomicroscope in insect saline $(1.80 \mathrm{~g}$ $\mathrm{NaCl} ; 1.88 \mathrm{~g} \mathrm{KCl} ; 0.16 \mathrm{~g} \mathrm{CaCl}_{2} ; 0.004 \mathrm{~g} \mathrm{NaHCO}_{3}$ and destiled water q.s.p. $100 \mathrm{ml}$ ). The digestive tubes were carefully placed on slide and fixed in $10 \%$ buffered formalin. Each portion of the digestive tube was measured using a micrometric eye piece and drawings were made with camera lucida. Photographs were also made using a $35 \mathrm{~mm}$ camera and $55 \mathrm{~mm}$ aproximation lens.

\section{RESULTS}

\section{THE DIGESTIVE TUBE}

The digestive tube of $D$. hominis larva is well developed and grows as the larva become older until the pre-pupa period. After that, it diminishes gradually during the pupal period up to the imago emergence.

In the larva, the digestive tube starts immediately after the bucal cavity with a very thin and opaque light yellow pharynx that is followed by the translucent oesophagus. It passes through the cephalic ganglion and ends in the cardia. The cardia is a stiff-walled spherical structure.

The digestive tube continues with the midgut that is longer and wider than the previous portion; it is yellow and has transversal grooves on the external surface. On each side, the too yellow long Malpighian tubules fuse into a single one, before opening in the narrrow lumen of the digestive tube, between midgut and hindgut. The outline of the Malpighian tubules is irregular; because its linning giant cells are arranged in a cobblestone pattern.

The hindgut diameter is smaller than that of the midgut, has whitish wall and irregularities on its external surface, similar to bubbles. The last portion of the digestive tube is the rectum that in the adult appears dilated before it opens into the anus. 
The digestive tube is covered by layers of fat tissue and is mantained into the larval cavity by filaments that tie it to the larval wall; tracheae of several diameters penetrate through its wall.

\section{THE FOREGUT}

\section{The first portion of the digestive tube is the pharynx}

In the second instar larva (L2) its length and width are about $1.0 \mathrm{~mm}$ and $0.1 \mathrm{~mm}$, respectively. It is very difficult to distinguish the limit between pharynx and the oesophagus. They have the same width but, while the former is slightly yellowish and opaque the later is whitish and translucent. After molting to L3 the pharynx grows in length but it does not follows the larval growth; in old L3, weighting over $600 \mathrm{mg}$, its length is similar to that of the L2 (Tab. I). It was very difficult to individualize and to measure the pharynx in pupae and adults (Tab. II).

Table I. Length of the digestive tube of Dermatobia hominis larvae (L2 and L3).

\begin{tabular}{cccccccc}
\hline $\begin{array}{c}\text { Instar Weight } \\
(\mathrm{mg})\end{array}$ & $\begin{array}{c}\text { Pharynx } \\
(\mathrm{mm})\end{array}$ & $\begin{array}{c}\text { Oesophagus } \\
(\mathrm{mm})\end{array}$ & \multicolumn{1}{c}{$\begin{array}{c}\text { Cardia } \\
(\mathrm{mm})\end{array}$} & \multicolumn{1}{c}{$\begin{array}{c}\text { Midgut } \\
(\mathrm{mm})\end{array}$} & \multicolumn{1}{c}{$\begin{array}{c}\text { Hindgut } \\
(\mathrm{mm})\end{array}$} \\
\hline $\mathrm{L} 2$ & 35 & $1.01 \pm 0.25$ & $1.20 \pm 0.00$ & $0.32 \pm 0.01$ & $13.75 \pm 0.35$ & $20.20 \pm 0.28$ \\
& 47 & $1.03 \pm 0.31$ & $1.28 \pm 0.30$ & $0.37 \pm 0.03$ & $10.56 \pm 0.45$ & $18.77 \pm 0.41$ \\
& 50 & $1.15 \pm 0.07$ & $1.33 \pm 0.10$ & $0.33 \pm 0.05$ & $7.84 \pm 0.20$ & $19.27 \pm 0.06$ \\
$\mathrm{~L} 3$ & 78 & $1.36 \pm 0.06$ & $2.29 \pm 0.01$ & $0.42 \pm 0.01$ & $15.30 \pm 0.36$ & $25.52 \pm 0.55$ \\
& 110 & $1.29 \pm 0.02$ & $2.29 \pm 0.01$ & $0.70 \pm 0.02$ & $22.97 \pm 0.15$ & $28.43 \pm 0.39$ \\
& 230 & $0.87 \pm 0.04$ & $2.34 \pm 0.08$ & $0.70 \pm 0.02$ & $23.95 \pm 0.07$ & $30.77 \pm 0.96$ \\
& 300 & $0.69 \pm 0.07$ & $2.30 \pm 0.01$ & $0.70 \pm 0.01$ & $24.10 \pm 0.14$ & $29.35 \pm 0.78$ \\
& 400 & $0.76 \pm 0.04$ & $2.49 \pm 0.21$ & $0.69 \pm 0.03$ & $22.26 \pm 1.59$ & $31.21 \pm 1.03$ \\
& 500 & $*$ & $3.29 \pm 0.01$ & $1.12 \pm 0.03$ & $28.85 \pm 0.21$ & $35.80 \pm 0.28$ \\
& 530 & $1.25 \pm 0.07$ & $3.08 \pm 0.03$ & $1.15 \pm 0.07$ & $27.80 \pm 1.56$ & $36.15 \pm 0.21$ \\
& 600 & $1.25 \pm 0.07$ & $2.68 \pm 0.11$ & $0.79 \pm 0.01$ & $30.55 \pm 0.64$ & $*$ \\
& 620 & $1.17 \pm 0.04$ & $2.72 \pm 0.11$ & $0.78 \pm 0.02$ & $30.50 \pm 0.44$ & $35.23 \pm 1.10$ \\
\hline
\end{tabular}

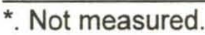

\section{The oesophagus}

In L2 the oesophagus has a length of about $1.2 \mathrm{~mm}$, with the width varying between 0.1 and $0.2 \mathrm{~mm}$. In early L3 the length duplicates but it does not follows the L3 growth (Tab. I). In pupae and adults the oesophagus decreases in lenght and width (Tab. II).

\section{The cardia}

Is a prominent structure of the digestive tube in the larva; in L2 it is a pearly in color $0.3 \mathrm{~mm}$ sphere shaped, hard structure into which anterior face, the oesophagus penetrates. In L3 it enlarges and becomes ovoid achieving $1.1 \mathrm{~mm}$ by $0.8 \mathrm{~mm}$ (Tab. I, Fig. 1a). During the pupal period and in the adult, it diminishes and becomes again spherical (Tab. II, Figs 2a, 2b).

\section{THE MIDGUT}

In larvae the midgut is a long yellowish tube of uniform width that narrows at the limit with the hindgut where the Malpighian tubules open. Midgut length 
varies with the development of the larva; while the width stays about $0.4 \mathrm{~mm}$, the length grows from $11 \mathrm{~mm}$ in L2 to $31 \mathrm{~mm}$ in old L3 (Tab. I, Fig. 1a).

In young pupae this length is about $18 \mathrm{~mm}$, diminishes until the $20^{\text {th }}$ day to

Table II. Length in pupae and adults of Dermatobia hominis digestive tube.

\begin{tabular}{|c|c|c|c|c|c|c|c|c|c|c|c|c|}
\hline \multirow{2}{*}{$\begin{array}{c}\begin{array}{c}\text { Pupae } \\
\text { (days) }\end{array} \\
1\end{array}$} & \multicolumn{2}{|c|}{$\begin{array}{l}\text { Pharynx } \\
(\mathrm{mm})\end{array}$} & \multicolumn{3}{|c|}{$\begin{array}{l}\text { Oesophagus } \\
(\mathrm{mm})\end{array}$} & \multicolumn{3}{|c|}{$\begin{array}{l}\text { Cardia } \\
(\mathrm{mm})\end{array}$} & \multicolumn{2}{|c|}{$\begin{array}{c}\text { Midgut } \\
(\mathrm{mm})\end{array}$} & \multicolumn{2}{|c|}{$\begin{array}{l}\text { Hindgut } \\
(\mathrm{mm})\end{array}$} \\
\hline & & & 2.67 & \pm & 0.06 & 0.68 & \pm & 0.02 & $17.35 \pm$ & 0.35 & $32.10 \pm$ & 0.26 \\
\hline 2 & 0.90 & \pm 0.30 & 2.38 & \pm & 0.83 & 0.44 & \pm & 0.12 & $18.13 \pm$ & 3.12 & $34.95 \pm$ & 3.36 \\
\hline 3 & 0.70 & \pm 0.02 & 2.33 & \pm & 0.41 & 0.60 & \pm & 0.06 & $16.17 \pm$ & 0.17 & $34.43 \pm$ & 0.59 \\
\hline 4 & & * & 3.18 & \pm & 0.08 & 0.65 & \pm & 0.03 & $14.20 \pm$ & 0.28 & $34.00 \pm$ & 2.91 \\
\hline 5 & & * & & * & & 0.73 & \pm & 0.04 & $8.43 \pm$ & 0.65 & $35.48 \pm$ & 0.35 \\
\hline 7 & & * & 1.26 & \pm & 0.10 & 0.20 & \pm & 0.03 & $7.59 \pm$ & 0.69 & $33.64 \pm$ & 2.27 \\
\hline 8 & & * & 0.74 & \pm & 0.15 & 0.47 & \pm & 0.17 & $4.45 \pm$ & 0.73 & $26.77 \pm$ & 5.57 \\
\hline 9 & & * & & * & & 0.33 & \pm & 0.04 & $3.78 \pm$ & 0.12 & $30.66 \pm$ & 1.66 \\
\hline 10 & & * & 0.13 & \pm & 0.20 & 0.30 & \pm & 0.10 & $4.88 \pm$ & 0.68 & $18.48 \pm$ & 3.82 \\
\hline 11 & & * & & * & & 0.32 & \pm & 0.10 & $4.05 \pm$ & 1.06 & $23.00 \pm$ & $=0.57$ \\
\hline 12 & & * & 0.64 & \pm & 0.03 & 0.25 & \pm & 0.04 & $5.78 \pm$ & 1.29 & * & 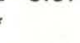 \\
\hline 13 & & * & 0.58 & \pm & 0.06 & 0.25 & \pm & 0.01 & $4.68 \pm$ & 0.68 & $16.44 \pm$ & $=2.04$ \\
\hline 15 & & * & 0.84 & \pm & 0.21 & 0.27 & \pm & 0.08 & $7.47 \pm$ & 0.04 & * & \\
\hline 16 & & * & 0.84 & \pm & 0.10 & 0.22 & \pm & 0.02 & $5.55 \pm$ & 0.47 & * & \\
\hline 17 & & * & 1.06 & \pm & 0.43 & 0.26 & \pm & 0.03 & $6.26 \pm$ & 0.06 & * & \\
\hline 19 & & * & 1.06 & \pm & 0.11 & 0.20 & \pm & 0.03 & $8.20 \pm$ & 0.06 & $4.05 \pm$ & $=0.64$ \\
\hline 22 & & * & 1.06 & \pm & 0.31 & 0.24 & \pm & 0.00 & $8.39 \pm$ & 3.13 & $8.38 \pm$ & $=2.54$ \\
\hline 23 & & * & 0.94 & \pm & 0.26 & 0.27 & \pm & 0.07 & $13.83 \pm$ & 1.83 & $9.41 \pm$ & 2.92 \\
\hline 24 & & * & 1.41 & \pm & 0.51 & 0.20 & \pm & 0.03 & $15.23 \pm$ & 0.63 & $12.36 \pm$ & $=4.79$ \\
\hline 26 & & * & & * & & 0.19 & \pm & 0.01 & $16.37 \pm$ & 0.69 & $9.40 \pm$ & $=0.71$ \\
\hline 29 & & * & 1.21 & \pm & 0.10 & 0.24 & \pm & 0.08 & $15.45 \pm$ & 1.91 & $10.29 \pm$ & $=0.30$ \\
\hline 30 & & * & 0.73 & \pm & 0.23 & 0.24 & \pm & 0.05 & $15.68 \pm$ & 2.22 & $9.51 \pm$ & $=0.30$ \\
\hline 31 & & * & 0.79 & \pm & 0.29 & 0.26 & \pm & 0.03 & $13.00 \pm$ & 1.21 & $10.84 \pm$ & $=0.56$ \\
\hline 32 & & * & & * & & 0.25 & \pm & 0.10 & $15.15 \pm$ & 1.45 & $12.27 \pm$ & $=0.24$ \\
\hline 33 & & * & 2.10 & \pm & 0.00 & 0.23 & \pm & 0.04 & $20.25 \pm$ & 6.15 & $11.66 \pm$ & 1.00 \\
\hline Adults & & * & 1.16 & \pm & 0.20 & 0.29 & \pm & 0.20 & $15.39 \pm$ & 1.93 & $9.58 \pm$ & 4.34 \\
\hline
\end{tabular}

${ }^{*}$. Not measured.

increase slowly up to the end of this stage. In the adults the midgut is still smaller showing an average length of $14.0 \mathrm{~mm}$ (Tab. II) (Figs 1b, 2a,b). The width is mantained around $0.2 \mathrm{~mm}$.

In larvae, the midgut shows transversal grooves throughout its length giving a plicate aspect to its wall; this is very delicate and in some regions looses the plicae to show small dilatations like bubbles of light and transparent wall (Fig. 1a). The characteristics of midgut in pupae and adults are quite different. Besides being shorter, in pupae, between the $8^{\text {th }}$ and $20^{\text {th }}$ day the midgut progressively takes a spindle shape; its wall is smooth and transparent allowing the observation of a yellowish material in its interior (Figs 1b, 2a). In pupae, more than 20 days old the midgut increases in length again, diminishes in width, but mantains the spindle shape dilatation, where one can observe through its transparent wall, a dark brown material (Fig. 2a). 

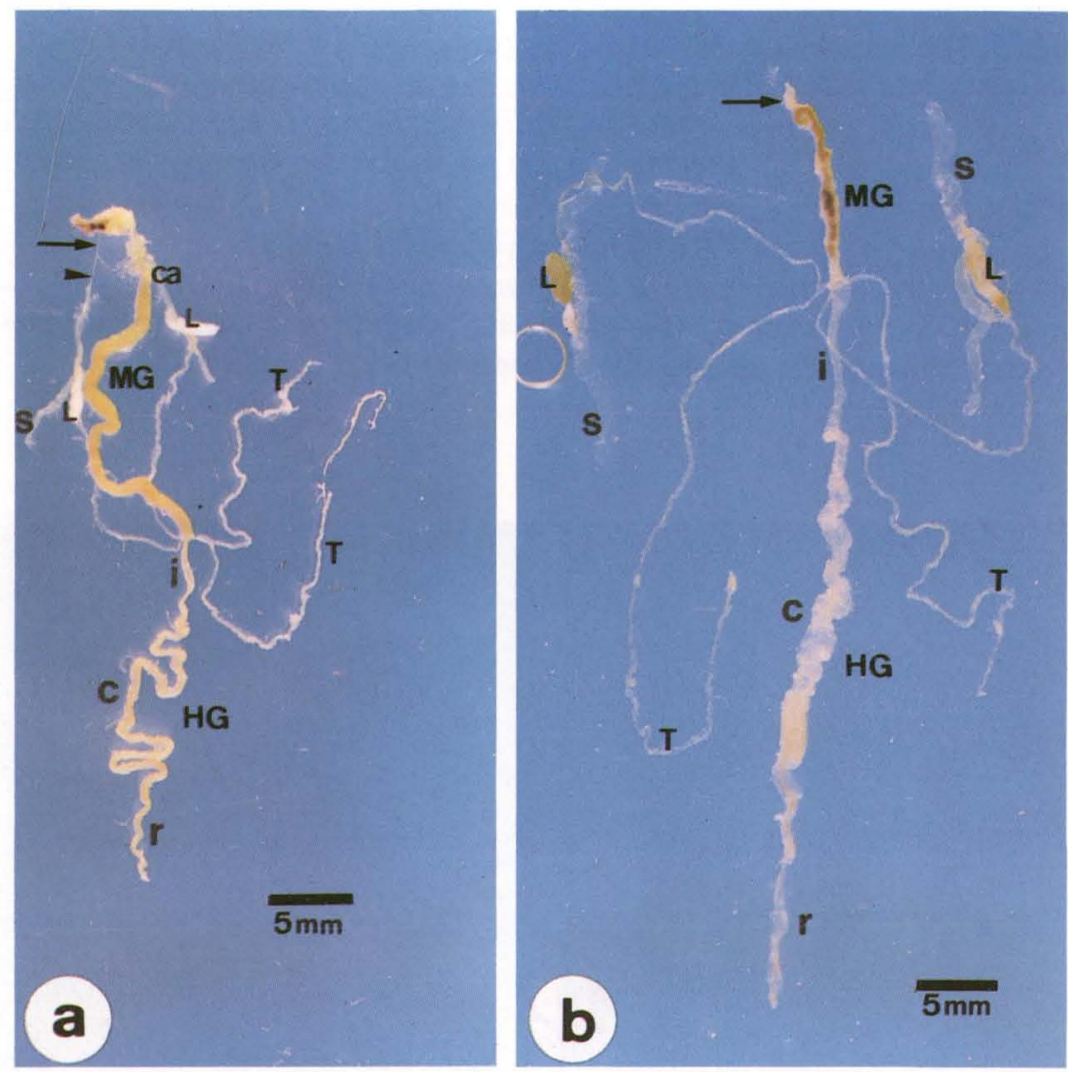

Fig. 1. Anatomy of the digestive tube of Dermatobia hominis. (1a) $3^{\text {rd }}$ instar larva, weithing $300 \mathrm{mg}$ (arrow $=$ common duct of salivary glands, arrow head $=$ duct of salivary gland); $(1 \mathrm{~b}$ ) eight days old pupa (arrow = cardia). Legends: (c) Colon; (ca) cardia; (HG) hindgut; (i) ileum; (L) lime gland; (MG) midgut; (r) rectum; (s) salivary gland; (T) Malpighian tubules.

Length and width of midgut are also smaller in adult than in old $D$. hominis pupa. It has two sharp portions: one belonging to the thorax and the other to the abdomen. The former shows a thin light smooth wall, while the abdominal portion is larger and shows transversal grooves (Fig. 2b).

\section{THE MALPIGHIAN TUBULES}

They form two pairs of very long, dark yellow, tangled, rosary-like tubules. They grow progressively during the larval instar up to 10 days pupa. In old pupa they decrease and are still smaller in the adult (Tabs III, IV).

Each pair joins in one single duct before penetrating laterally the digestive tube, in the limit between the midgut and the hindgut. Each duct shows a whitish smooth surface of variable length. In L2, L3 and young pupa this length is about $0.6 \mathrm{~mm}$. In pupa from 20 days up to adult, this length increases up to $2.5 \mathrm{~mm}$. One of the pairs, has on its distal end an ampule-like structure containing a white sticky 
material. They are well developed in larva and pupa, and are usually tied by tracheae to the salivary glands and to the faty tissue. The distal end of the other pair is tied by tracheae to the faty tissue and to the latero-posterior wall of the insect body (Figs la,b, 2a). In adults the Malpighian tubules are shorter and the ampulae diminish considerably (Fig. 2b).

The rosary aspect of the Malpighian tubules is due to the alternate arrangement of the giant cells that layed as a cobblestone monolayer wall. During the larval period there is no alteration in the Malpighian tubules, but in old pupa they loose the rosary aspect and in the adult they become whitish (Figs 1a,b, 2a).
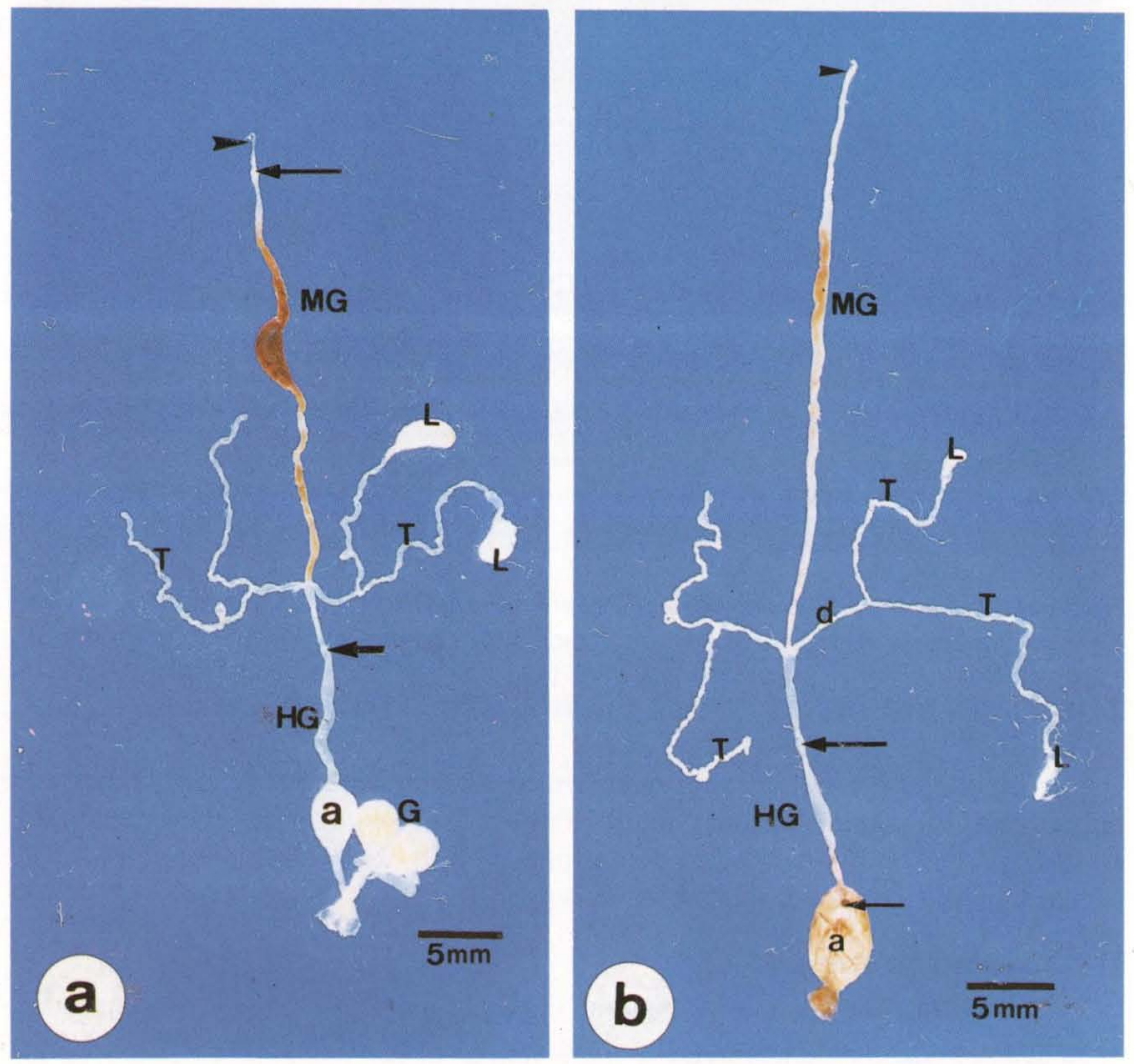

Fig. 2. Anatomy of the digestive tube of Dermatobia hominis. (2a) 24 days old pupa (long arrow = cardia, short arrow= rectal valvule, arrow head= oesophagus); (2b) adult (long arrow= rectal valvule; short arrow= rectal papillae; arrow head=cardia). Legends: (a) rectal ampule, (d) duct of Malpighian tubules, (G) gonads, (HG) hindgut, (L) lime gland, (MG) midgut, (T) Malpighian tubules. 
Table III. Length of Malpighian tubules and salivary gland of Dermatobia hominis larvae (L2 and L3).

\begin{tabular}{cccc}
\hline Instar & $\begin{array}{c}\text { Weight } \\
(\mathrm{mm})\end{array}$ & $\begin{array}{c}\text { Malpighian tubules } \\
(\mathrm{mm})\end{array}$ & $\begin{array}{c}\text { Salivary gland } \\
(\mathrm{mm})\end{array}$ \\
\hline L2 & 35 & $8.09 \pm 0.44$ & $3.92 \pm 0.06$ \\
& 47 & $8.66 \pm 0.00$ & $4.98 \pm 0.00$ \\
& 50 & $7.30 \pm 0.14$ & $4.30 \pm 0.14$ \\
L3 & 78 & $10.75 \pm 0.78$ & $8.55 \pm 0.21$ \\
& 110 & $15.90 \pm 0.42$ & $7.12 \pm 0.45$ \\
& 230 & $13.20 \pm 2.75$ & $7.50 \pm 0.42$ \\
& 300 & $16.95 \pm 0.21$ & $9.09 \pm 1.14$ \\
& 400 & $16.18 \pm 2.37$ & $9.73 \pm 0.84$ \\
& 500 & & $13.54 \pm 1.11$ \\
& 530 & $19.97 \pm 2.94$ & $10.31 \pm 0.16$ \\
& 620 & $18.15 \pm 4.71$ & $11.46 \pm 0.08$ \\
\hline
\end{tabular}

*. Not measured.

Table IV. Length of Malpighian tubules and salivary gland in pupae and adults of Dermatobia hominis.

\begin{tabular}{ccc}
\hline $\begin{array}{c}\text { Pupae } \\
\text { (days) }\end{array}$ & $\begin{array}{c}\text { Malpighian tubules } \\
(\mathrm{mm})\end{array}$ & $\begin{array}{c}\text { Salivary gland } \\
(\mathrm{mm})\end{array}$ \\
\hline 1 & $18.30 \pm 0.42$ & $14.00 \pm 1.41$ \\
2 & $26.14 \pm 4.14$ & $14.92 \pm 1.82$ \\
3 & $20.77 \pm 1.50$ & $15.60 \pm 1.70$ \\
4 & $18.90 \pm 2.93$ & $15.03 \pm 2.35$ \\
5 & $21.60 \pm 7.82$ & $14.20 \pm 1.53$ \\
6 & $30.70 \pm 0.71$ & $19.80 \pm 1.70$ \\
7 & $21.60 \pm 3.95$ & $12.90 \pm 1.25$ \\
8 & $19.55 \pm 5.13$ & $12.09 \pm 1.11$ \\
9 & $11.30 \pm 3.21$ & $12.50 \pm 3.01$ \\
10 & $16.83 \pm 4.98$ & $11.10 \pm 2.23$ \\
11 & $11.10 \pm 2.71$ & $8.10 \pm 0.42$ \\
13 & $9.00 \pm 3.39$ & $7.20 \pm 0.00$ \\
15 & $2.73 \pm 1.01$ & $*$ \\
19 & $6.75 \pm 2.70$ & $*$ \\
22 & $6.38 \pm 0.39$ & $4.82 \pm 0.04$ \\
23 & $8.65 \pm 2.25$ & $*$ \\
24 & $12.96 \pm 2.10$ & $*$ \\
26 & $11.53 \pm 1.36$ & $*$ \\
30 & $10.68 \pm 2.20$ & $*$ \\
31 & $11.34 \pm 2.31$ & $*$ \\
33 & $12.08 \pm 1.02$ & $*$ \\
Adults & $11.40 \pm 2.60$ & $*$ \\
\hline
\end{tabular}

*. Not measured.

\section{THE HINDGUT}

Is the segment of the digestive tube starting immediately after the opening of the Malpighian tubules, finishing in the anus. In L2 its length is almost constant 
but increases slowly and progressively in L3 up to pre-pupa. During the pupal period it diminishes progressively up to imago (Tab. I, II). The anatomic characteristics of the $D$. hominis hindgut vary according to the period of its development. During the larval period it has three portions: the ileum, the colon and the rectum. The ileum is a straight tube of light yellow or whitish hard wall, with a width smaller than the remainder hindgut and much smaller than the midgut. The second segment, the colon, is the longest portion. It is larger than the ileum but smaller than the midgut, and shows small nodules and dilatations here and there. Following is the rectum, having $1 / 10$ of the total length of the hindgut; it is narrower than the colon without nodules or dilatations (Fig. 1a). In pupa the ileum has the same size as the larva, but the wall looses gradually its hardness and becomes transparent (Figs 1b, 2a). In old pupa and adult it shows a small intumescence of the distal portion forming the rectal valvule. The colon diminishes progressively in length and width becoming, in the adult, indistinguishable from the ileum. The rectum changes considerably in the old pupa and in the adult. It may be subdivided in three regions: the anterior, starting at the rectal valvule, the median, forming third, the rectal ampule, and the anal rectum. The ampule is surrounded by many branched tracheae. In the adult the ampule has four anteriorlly located rectal papillae (Fig. 2a,b). The rectal ampule grows as the pupa develops. The new hatched imago has a large portion of its abdomen cavity occupied by the rectal ampule that empties after the meconium liberation. The ampule's color varies from yellow to dark brown (Fig. 2a,b).

\section{THE SALIVARY GLANDS}

In Dermatobia hominis there is a pair of salivary glands laying laterally in the anterior body cavity of the larva. They are tubular, whitish, sometimes transparent. Each gland has a very thin excretory canal which fuses in one single to open in the buccal cavity (Fig. 1a). Gland ducts and common ducts have equivalent lengths during the larval instars growing slowly during this period from $0.5 \mathrm{~mm}$ in L2 to $1.3 \mathrm{~mm}$ in full grow L3. The salivary glands are fixed by tracheae which tie them to the whitish ampule of the Malpighian tubules. Their development follows the larva's development. In L2 their length vary from $4.0 \mathrm{~mm}$ to $5.0 \mathrm{~mm}$. In early L3 they double this length and continue growing slowly reaching $12 \mathrm{~mm}$ in mature L3 (Tab. III). They still grow during the pupal period reaching about $20 \mathrm{~mm}$ in 13 days old pupa. But they are not seem in older pupae and adults (Tab. IV, Figs 2a,b).

\section{DISCUSSION}

The majority of papers dealing on insect digestive tube describe the adults. GRAHAM-SMITH (1934) describes a well developed oesophagus in adult Calliphora erythrocephala, considering the crop as an oesophagus' diverticulum. In D. hominis it was observed, that the oesophagus grows during the larval period, doubles its length after moulting to L3, but gradually diminishes during the pupal period up to the adult. $D$. hominis has no crop. This structure is not always found in muscoids, but occurs in feeding adult insects. SINGH \& JUDD (1966) described three species of non-feeding adult muscoid: Hypoderma lineatum, Cephenemya apicata and Cuterebra latifrons; all but the later show no crop. Our observations on D. hominis follow the rule, as this species do not feed as adult. 
The cardia is described as well developed in feeding adult muscoid Diptera (Wigglesworth 1929, 1972; Graham-SMith 1934; Miller 1950; King 1988, $1989,1991)$. Nevertheless, SINGH \& JUDD (1966) compared the cardia in feeding and non-feeding adult muscoids and verified that in the later, the cardia is considerably smaller. In D. hominis it was observed, that the cardia is well developed in larvae and diminishes during the pupal period being almost indistinguishable in the adult. This is in accordance to the observed by SINGH \& JUDD (1966) in the non-feeding adult muscoid.

The midgut is the portion where nutrients are absorbed and enzimes secreted, presenting variable features depending on the species and stage studied. All but one paper on Diptera midgut refers to adults. GRAHAM-SMITH (1934) describes the midgut in adult C. erythrocephala as a straight long narrow tubule in the thoracic portion; immediately after penetrating the abdominal cavity, the tubule enlarges for a few length, than narrows giving several turns in spiral to become straigth only at its end. Same features were observed in Hylemya brassicae and Sarcophaga bullata (Dixon, 1952) and in other feeding adult Diptera (IMMS 1957). This later author describes the midgut as tubular in the calyptratae muscoid larvae refering that it is more developed in this stage than in the adult. SINGH \& JUDD (1966) compared the digestive tube in both, feeding and non-feeding adult muscoid; they found, for the former, the same as the authors above, but in the non-feeding adult muscoid the midgut is a narrow tubule running straight throught the thoracic and abdominal regions.

The observations on adult $D$. hominis are similar to those of SINGH \& JUDD (1966) on the non-feeding adult muscoids. Comparing this portion in the larva and the adult it was found that its size is less than half in the latter. This is expected since the adult $D$. hominis lives about nine days without feeding; it is wise that the nature reserved the majority of the abdominal cavity to the reproductive organs.

Dermatobia hominis Malpighian tubules have the same morphology and sizes of the other described Diptera (GRAHAM-SMITH 1934; SNODGRASS 1935; OWSLEY 1946; DEMEREC 1950; IMMS 1957; SINGH \& JUDD 1966). There is some controversy concerning the level of the opening of their common ducts in the digestive tract. Some say that they open in the limit between the midgut and the hindgut (GRAHAM-SMITH 1934; SNODGRASS 1935; HENSON 1944; OWSLEY 1946; Miller 1950; WeSt 1951; SINGH \& JUDD 1966). Nevertheless, RoBERTSON (1936), WigGLESWORTH (1939) apud DEMEREC (1950) have the opinion that they open directely in the midgut, while POULSON (1937) affirms that they open at the beginning of the hindgut. In spite of this, all are in accordance that the common ducts open at slightly different levels. It was also observed this in D. hominis, and analysis of histologic sections (n.p.) showed that they open at the distal end of the midgut. Development of the Malpighian tubules reaches the peak during the larval period. In pupa and adult, besides being smaller they change their features, becomming yellow pale and loosing their rosary aspect. The two whitish ampulae at their distal end, known as lime glands, are well developed in the larva and almost imperceptible in the adult. These observation are in accordance with the described for the majority of Diptera (HERBST \& BRADLEY 1989); the only difference is that 
in some species as Drosophila hydei (Hevert, 1975), Lucilia cuprina (Waterhouse, 1950) and Musca autumnalis (Grodowitz \& Broce, 1983) these ampulae are located in the middle of the Malpighian tubules.

The hindgut is subdivided in different portions and receives different denominations depending the species and the author. According to SNODGRASS (1935), DEMEREC (1950), MEGAHED (1956) and CHRISTOPHERS (1960) the larva's hindgut has three portions: the ileum, beginning immediately after the opening of the Malpighian tubules, characterized by being a narrow and straight portion; the colon following the ileum, characterized by being long convoluted and having dilated spots along its length; the rectum, narrower and shorter than the colon, with no dilations on its wall. The present observations on $D$. hominis larvae agree with these authors.

The descriptions in adults are more heterogeneous. The hindgut is divided basically in two portions: the anterior, before the rectal valvule and the posterior, both receiving different denomination by the different authors. SINGH \& JUDD (1966) used the name "ileum" to the anterior portion, the same denomination given by MINCHIN (1905) and TOWNSEND $(1934,1942)$ apud SINGH \& JUDD (1966) coined the same portion, "colon", and OWSLEY (1946) used both "ileum" and "colon" for it. GRAHAM-SMITH (1934), OWSLEY (1946) and DIXON (1952) divided the posterior portion in two regions and called them as "pouch rectal" and "anal rectum". On the other hand, SNODGRASS (1935) divided all the hindgut in "ileum", "colon", "rectal sac" and "rectum", with no mention to the rectal valvule.

DEMEREC (1950) observed that the localization of the rectal valvule varied along the hindgut, and that some of them were too close to the rectal ampule, as he showed in Drosophila melanogaster.

HoRI (1960, 1961, 1962a,b), studying 82 species of feeding adult muscoid, consider that the species having long hindgut and rectal valvule too close to the rectal ampule belongs to more recent groups of insects. This is denied by SINGH \& JUDD (1966) who found rectal valvule far from the rectal ampule in recent groups, as are in the non-feeding adults muscoid, H. lineatum, C. latifrons and C. apicata. Its agree with these later authors, because it was also observed in adult $D$. hominis, that belongs to recent groups, the rectal valvule, far from the rectal ampule.

The observation on the salivary glands during the larval period of Dermatobia hominis are in accordance with what is described for other Diptera. Nevertheless in pupa and adult there had some differences. In feeding adult muscoids, they keep growing and, after metamorphosis, they develop from the imaginal disc present at the beginning of the secretory portion (GRAHAM-SMITH 1934; KOBAYASHI 1934; Ross 1939; SINGH \& JUDD 1966). In the non-feeding adult muscoids as in C. apicata and $H$. lineatum, they are present in the pupa but not in the adult (SINGH \& JUDD 1966). It was observed the salivary gland development in $D$. hominis up to the $12^{\text {th }}$ day of pupation, when the ducts were very short and the secretory portions were whitish and opaque showing aspects of degeneration. No salivary gland was found in the adult. 


\section{REFERENCES}

BAIRD, C.R. \& AKRE, R.D. 1977. Morphology of alimentary and reproductive tracts the Rodent Bot fly, Cuterebra tenebrosa (Diptera:Cuterebridae). J. Entomol. Soc. Brit. Columbia 74: 27-31.

CHRISTOPHERS, S.R. 1960. Aedes aegypti (L.), the yellow fever mosquito. Its life history, bionomics and structure. Cambridge, Cambridge Univ. Press, 739p.

DEMEREC, M. 1950. Biology of Drosophila. New York, J. Wiley and Sons, 632p.

DIXON, S.E. 1952. The anatomy and histology of the digestive tract of Hylemya brassicae (Bouché) (Diptera: Anthomyiidae). Rep. Entomol. Soc. Ontario 82: 47-60.

GRAHAM-SMITH, G.S. 1934. The alimentary canal of Calliphora erythrocephala L., with special reference to its musculature and to the proventriculus, rectal valve and rectal papillae. Parasitology 26: 176-248.

HENSON, H. 1944. The development of the Malpighian tubules of Blatta orientalis (Orthoptera). Proc. Roy. Entomol. Soc. Lond. 19: 73-91.

HERBST, D.B. \& BRADLEY, T.J. 1989. The Malpighian tubule lime gland in an insect inhabiting alkaline salt lakes. J. Exp. Biol. 145: 63-78.

HORI, K. 1960. Comparative anatomy of the internal organs of the calyptratae muscoid flies. I. Male internal sexual organs of the adult flies. Sci. Rep. Kanazawa Univ. 7: 23-83.

1961. Comparative anatomy of the internal organs of the calyptratae muscoid flies. II. Female internal sexual organs of the adult flies. Sci. Rep. Kanazawa Univ. 7: 61-101.

1962a. Comparative anatomy of the internal organs of the calyptratae muscoid flies. III. The alimentary canal of adult flies. Sci. Rep. Kanazawa. Univ. 8: 69-88.

1962b. Comparative anatomy of the internal organs of the calyptratae muscoid flies. IV. The Malpighian tubules of the adult flies. Sci. Rep. Kanazawa. Univ. 8: 89-106.

IMMS, A.D. 1957. A General Textbook of Entomology. London, Methuen \& Co. Ltd., $3^{\text {th }}$ ed., 886 p.

KING, D.G. 1988. Cellular Organization and Peritrophic membrane formation in the cardia (Proventriculus) of Drosophila melanogaster. Jour. Morphol. 196: 253-282.

1989. Phylogenetic diversity of cellular organization in the cardia of muscoid flies (Diptera:Schizophora). Jour. Morphol. 202: 435-455.

1991. The origin of an organ: Phylogenetic analysis of evolutionary innovation in the digestive tract of flies (Insecta: Diptera). Evolution. 45: 568-588.

KobAyASHI, K. 1934. Studies on the internal anatomy of the Trypaneidae (fruit-flies). Trans. Natur. Hist. Soc. Formosa 24 (131): 136-149.

MEGAHED, M.M. 1956. Anatomy and histology of the alimentary tract of the female of the biting midge Culicoides nubeculosus Meigen (Diptera: Heleidae: 
Ceratopogonidae). Parasitology. 46: 22-47.

Miller, A. 1950. Biology of Drosophila, p.424-442. In: M. DEMEREC (Ed.). The internal anatomy and histology of the imago of Drosophila melanogaster. New York, John Wiley \& Sons Inc, 632p.

OKADA, T. 1954a. Comparative morphology of the drosophilid flies. V. Convolution of the proximal intestine in the adult flies. Zool. Mag. Tokyo. 63: 157-261.

1954b. Comparative morphology of the drosophilid flies. VI. Rectal papillae, their mumber, arragement and shape. Zool. Mag. Tokyo. 63: 262-265. OWSLEY, W.M.B. 1946. The comparative morphology of internal structures of the Asilidae (Diptera). Ann. Entomol. Soc. Amer. 39: 33-68.

Poulson, D.F. 1937. The embryonic development of Drosophila melanogaster. Actualités Sci. et ind., Hermann et Cie, 1: 1-51.

ROBERTSON, C.W. 1936. Metamorphosis of Drosophila melanogaster, including and accurately timed account of the principal morphological changes. Jour.

Morphol. 59: 351-399.

Ross, E.B. 1939. The post-embryonic development of the salivary glands of Drosophila melanogaster. Jour. Mophol. 65: 471-495.

SINGH, S.B. \& W.W. JUDD. 1966. A comparative study of the alimentary canal of adult Calyptratae (Diptera). Proc. Entomol. Soc. Ont. 96: 29-80.

SNODGRass, R.E. 1935. Principles of Insect Morphology. The Alimentary Canal. New York, McGraw-Hill Book Co., 667p.

West, L.S. 1951. The housefly. New York, Comstock Publ. Co. Ithaca, 584p.

Wigglesworth, V.B. 1929. Digestion in tsetse-fly: a study of structure and function. Parasitology 21: 288-321.

1972. The Principles of Insect Physiology. New York, John Wiley \& Sons Inc., 7th ed., 820p.

Recebido em 08.V.1996; aceito em 27.XII.1996. 